\title{
Food Energy Cost of Overweight and Obesity: A Model to Estimate the Amount of Food Expended for Excess Body Weight in a Community
}

\section{Habte TY* and Krawinkel M}

Nutrition in Developing Countries, Institute of Human Nutrition, Justus-Liebig-University Giessen, Germany

${ }^{*}$ Corresponding author: Habte TY, PhD, Nutrition in Developing Countries, Wilhelmstrasse 20, 35392

Giessen, Germany, E-mail: Tsige-Yhannes.Habte@ernaehrung.uni-giessen.de

Citation: Habte TY, Krawinkel M (2015) Food Energy Cost of Overweight and Obesity: A Model to

Estimate the Amount of Food Expended for Excess Body Weight in A Community. J Nutr Health Sci 2(3):

302 . doi: 10.15744/2393-9060.2.302

Received Date: April 20, 2015 Accepted Date: August 24, 2015 Published Date: August 25, 2015

\begin{abstract}
Over-consumption of food energy entails body fat accumulation, overweight, obesity and increased risks of diseases. It is also indirectly associated with poor body condition followed by forced rest periods and limitations of activities and tasks. At community or global level, excess body weight could indirectly influence the environment by advancing food demand and the pressure on food production resources. The extent to which the environment is impacted can be estimated based on the level of excess food produced and consumed at community level. In order to determine the extra food energy required to produce and maintain excess weight, two mathematical models are designed. The concept of food energy partition, a method of determining excess weight in gender and age classes plus some information on the conversion efficiency of food energy to body fat, energy value of body fat, energy value of food, and total energy expenditure for excess weight are considered and applied in order to achieve the desired goal. Together with the affected size of a population, it was possible to estimate the additional cost of food energy for overweight and obesity. As an example, average extra global food energy expended for the excess weight in the existing population is calculated as 659.495 million $\mathrm{Gcal}(\mathrm{Gcal}=1000 \mathrm{Mcal})$ or 261.681 million tons and that for the maintenance of excess body weight or the total energy expenditure for excess bodyweight, as 239.8 million Gcal/year or 95.07 million tons per year. Assuming that the global average annual food production per hectare is 2.64 tons, 95.07 million hectare land is required for the production of food to meet the cost for excess body weight, and 36.43 million hectare per year to meet the cost of the maintenance of the excess body weight. These values form the basis for the estimation of the extra load on environmental resources and impacts in terms of soil, water- and atmosphere degradation and the indirect influence on health and wellbeing. Considering the wide range of variability in body structure and food type and quality in the world, which could inflict relatively higher analytical error, the model is best fit to small communities with minor inherent and treatment differences.

Keywords: Overweight; Obesity; Food energy partition; Conversation efficiency of food to fat; Energy value of fat and common food; Gender class; Age class
\end{abstract}

\section{Introduction}

Overweight and obesity are well-recognized global public health risks that cause a range of diseases including cardiovascular disorders, hypertension, stroke, type 2 diabetes mellitus, osteoarthritis and certain cancers [1,2]. At the beginning of the twenty first century, they caused $47 \%$ of global burden of diseases and almost $60 \%$ of the 56 million deaths [3]. Over consumption of unhealthy food that predominantly consists of high level of energy-dense, nutrient poor diets that are high in fat, sugar and salt, compounded with low level of physical activity are the major causes of excessive body weight and the associated diseases [4].

Once associated with wealthy countries, overweight and obesity are now prevalent in low and middle-income countries as well [5]. The prevalence of overweight (35\%) and obesity (19\%) in the developed countries is relatively higher than in the developing countries where they lie at $20.3 \%$ and $6.7 \%$ respectively [6]. In the years until 2030, the prevalence in the developing regions is expected to grow substantially [6]. In view of the social values attributed to bigger body structure, and their consideration as the symbol of high social status, the expectation is probably valid [7].

According to a survey conducted between early 1990 and 2005, about 31.4\% of the women in urban Africa were overweight or obese; even though some variability between countries are attributed to the levels in economic development and urbanization, the trend has been rising with more intensity among the poor [8]. Another survey conducted in 2005 showed $9.95 \%$ of young adults (20-39 years old) in SSA to be overweight and 2.2\% to be obese; for the age groups $40-70$ years old the prevalence of overweight and obesity were $16.93 \%$ and $5.13 \%$ respectively [6]. In 1990 the estimated overweight and obesity in Africa were $8.5 \%$ and $7.4 \%$ respectively, and these were projected to reach $12.7 \%$ and $10.6 \%$ in 2020 [9]. People tend to eat more without reporting satiety when they are served larger portions, and increased serving has been implicated in the development of obesity; it has, therefore been recommended to control the portion of diets in order to balance energy intake and manage body weight [10]. 
A relatively large body of evidence shows that overweight and obesity have adverse consequences on premature physical morbidity and mortality [11]. However, food energy cost for the development of excess weight in a community is yet to be known. The information is essential for policy and strategic interventions on social, economic and environmental concerns. Therefore, it is planned to develop a model for estimating the minimum average food energy cost of overweight and obesity in a community. An operational test of the model will be conducted as an example using the global data on overweight, obesity and the population affected as classified according to sex and age groups. The outcome will show the minimum level of extra amount of food expended to produce the excess weight.

\section{Materials and methods}

\section{The concept of the evaluation of food energy cost for overweight and obesity}

The food ingested passes through the processes of digestion, absorption, circulation and metabolism before it avails its energy for body maintenance, tissue accretion and physical activity or work. In the process, a certain fraction of food energy is lost as fecal-, gaseous-, urine- and heat energy (Figure 1). At an individual level, the losses can vary based on internal factors, (differences in the functions of the digestive system, absorption and metabolism), and external factors including the nature and level of food consumed. At community level, however, the mean of sizable data from the population can give representative or reference energy loss. The efficiency of conversion of food energy to stored energy, [(GE - Energy losses/GE) x 100] X food energy, gives net energy for fat deposition (NEf); and the inverse of the efficiency of conversion of food energy times stored energy as fat (NEf) can give the part of food energy used for fat energy deposition (GEf).

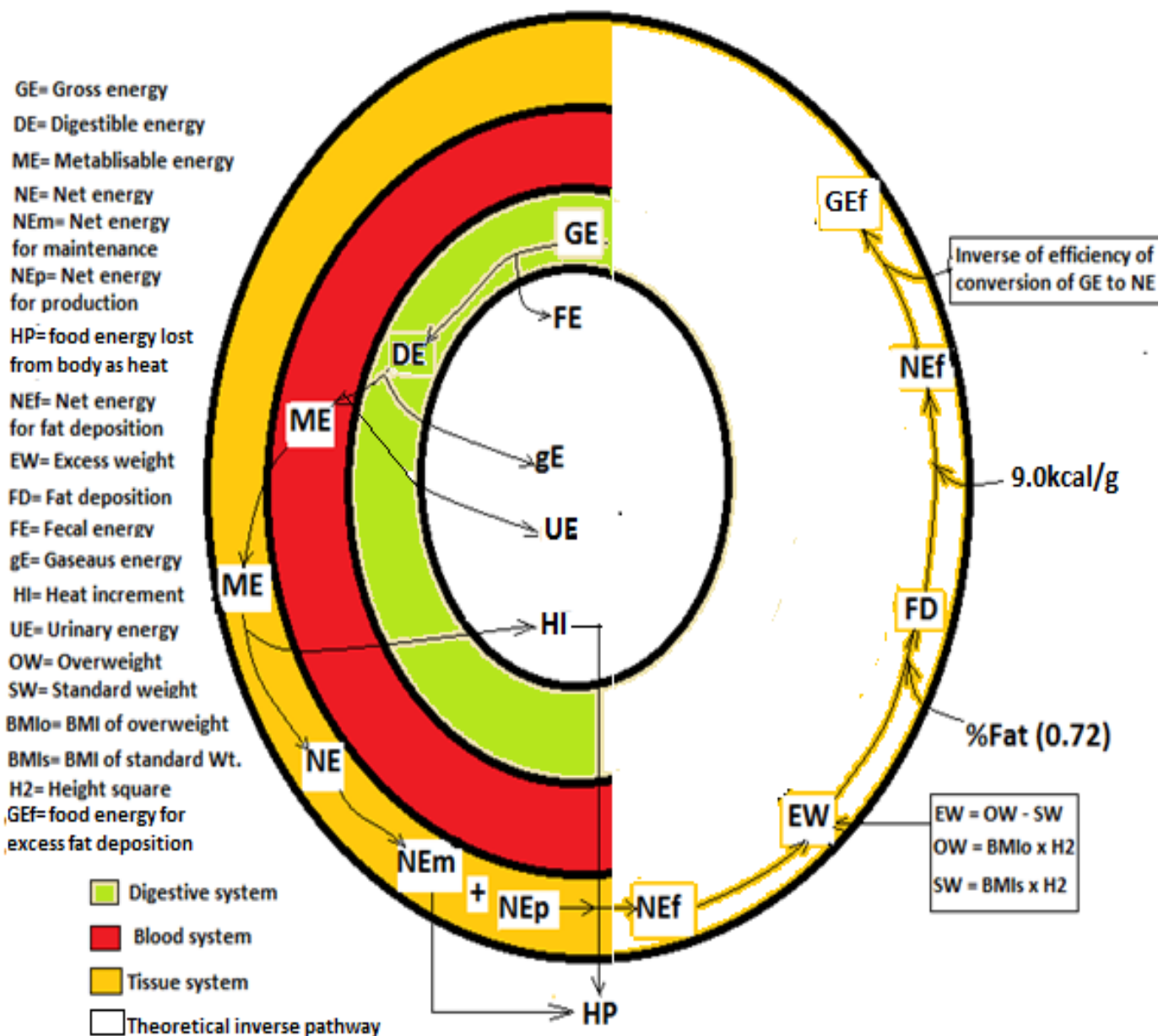

Figure 1: The direct and inverse processes of GE transformation as the basis for the calculation of the cost of food-energy for overweight

Standard body mass index (BMI) and height for age and gender groups [12] provide the information for calculation the body weight of normal (reference), overweight and obese people. The differences between reference weight and overweight or obese weight give excess weight. Excess weight predominantly consists of fat, which accounts for about 72\% excess weight [13]. The energy value of body fat $(9.0 \mathrm{kcal} / \mathrm{g})$ together with the inverse of the efficiency of conversion (3.3) of GE to net energy for fat deposition [14] lead to the estimation of the cost of food energy for overweight and obesity. The energy cost for fat deposition or excess weight does not only consist of food energy for accretion but also that for maintenance. The latter is considered in the calculation of the food energy cost of excess weight by using basal metabolic rate (BMR) and physical activity level (PAL) which gives total energy expenditure (TEE). 


\section{Procedures}

The methods of determining excess body weight (the weight exceeding the "normal" body weight), the fat content of the excess weight, the energy deposited as excess fat, the cost of food energy for excess weight, the total energy expenditure (TEE) and the level of common diet that lead to overweight and obese weight are described under this topic. At first, the assumptions considered to proceed with the procedures are given.

Assumptions: 1. Excess weight in either overweight or obesity predominantly results from the accumulation of fat in the adipose tissue.

2. At community level the average efficiency of food conversion, the reference weight and height for defined age and gender groups and the standard BMI cutoff points $[12,15,16]$ for normal weight, overweight and obesity are representative measures of body and nutritional status.

Excess bodyweight in overweight and obesity: The characterization of body status as underweight, overweight and obesity is based on body mass index (BMI). The lower limits of BMI for both overweight and obesity, and the upper limit for underweight are the cutoff points of nutritional status [12]. If the BMI and body height of specific classes of age and gender groups are known (Tables 1 and 2), then the body weight can be derived from their relationship (BMI = Weight $\mathrm{kg} / \mathrm{Height}^{2}$ ).

\begin{tabular}{|c|c|c|c|c|c|c|}
\hline \multirow{2}{*}{ Age (years) } & \multicolumn{3}{|c|}{ Male $\left(\mathrm{BMI} \mathbf{k g} / \mathrm{m}^{2}\right)$} & \multicolumn{3}{|c|}{ Female (BMI $\mathrm{kg} / \mathrm{m}^{2}$ ) } \\
\hline & Underweight & Overweight & Obese & Underweight & Overweight & Obese \\
\hline $2-<5$ & 14.21 & 17.79 & 19.53 & 13.94 & 17.58 & 19.54 \\
\hline $5-<10$ & 14.22 & 18.45 & 21.51 & 14.08 & 18.33 & 21.47 \\
\hline $10-<15$ & 15.8 & 21.75 & 26.57 & 16.11 & 22.26 & 27.27 \\
\hline $15-18$ & 17.91 & 24.31 & 29.29 & 18.14 & 24.6 & 29.58 \\
\hline$>18$ & 18.5 & 25.0 & 30.0 & 18.5 & 25 & 30 \\
\hline
\end{tabular}

Source: Cole et al. 2007 [12]

Table 1: The BMI cut-off points: upper limits of underweight and lower limits of overweight and obesity

\begin{tabular}{|c|c|c|c|c|c|c|}
\hline \multirow{2}{*}{$\begin{array}{c}\text { Age } \\
\text { (years) }\end{array}$} & \multicolumn{3}{|c|}{ Male } & \multicolumn{3}{|c|}{ Female } \\
\hline & BMI kg/m ${ }^{2}$ & Height $\mathrm{cm}$ & Weight kg & BMI kg/m ${ }^{2}$ & Height $\mathrm{cm}$ & Weight kg \\
\hline $2-<5$ & 15.01 & 101 & 15.31 & 15.54 & 100 & 14.92 \\
\hline $5-<10$ & 15.71 & 124 & 24.46 & 15.72 & 124 & 24.34 \\
\hline $10-<15$ & 18.03 & 153 & 42.92 & 18.46 & 152 & 43.3 \\
\hline $15-18$ & 20.87 & 173 & 62.8 & 20.86 & 163 & 55.36 \\
\hline$>18$ & 22.19 & 177 & 69.52 & 21.43 & 163 & 56.94 \\
\hline
\end{tabular}

Sources: WHO. 2006, 2007 [15,16]; Marshal W A. 1981[17]

Table 2: Mean reference [normal] BMI, height, and normal weight

The differences between overweight or obese weight and reference weight of each sex and age class give the classified excess weight (Table 7).

The energy value of excess weight: Human body can be compartmentalized either in four (body water, protein, fat and minerals) or two parts (fat mass and fat-free-mass). In adult men and women, changes in body weight and body composition are associated with nutrition and life style; with excess food consumption than required, the body weight and body fat mass increase, whereas fat-free-mass hardly changes [18]. Excess weight is predominantly the result of fat deposition and the mean fat mass of excess weight is estimated at $72 \%[13,19]$. Based on this background and the ease of determining the energy content of excess weight, the two-compartment method of analyzing the composition of excess weight is preferred. Excess weight multiplied by the coefficient of its fat content (0.72) gives the mass of excess fat deposited in the body. The average energy value of body fat is $9.0 \mathrm{kcal} / \mathrm{g}$ [20]; excess weight in $\mathrm{kg}$ times the energy concentration of body fat $(9.0 \mathrm{Mcal} / \mathrm{kg})$ gives the energy value of excess weight.

Total energy expenditure [TEE] and the energy deposited in excess weight: The energy expended for excess weight in both overweight and obesity consists of two components: 1) the energy used to synthesize body fat, the basal metabolic rate (BMR) of excess weight and the minimum energy cost of physical activity attributable to excess weight, all account to the total energy expenditure (TEE); and 2) the energy deposited as fat. The FAO [21] provides equations to calculate the basal metabolic rate of different gender and age groups (Table 3). The classification of the age groups in this reference is of wider range than the one in this work. Some adjustment was, therefore, necessary in the classification of age groups in order to fit to that of this work. The equation given for $3-10$ years age groups (Table 3 ) is modified to apply to age groups $2-<5$ and $5-<10$ years; that of the $10-18$ years is classified to be used for age groups $10-<15$ and $15-18$ years and that of $>18$ years remain as it is. By doing so, the error that could arise from wide range of body weight differences is minimized. Total energy expenditure is the product of basal metabolic rate $(\mathrm{BMR})$ and physical activity level (PAL); (TEE = BMR $x$ PAL). The equations (Table 3 ) and the values of physical activity level (Table 4) are coined from FAO 2001 [21]. 


\begin{tabular}{|c|c|c|}
\hline Age years & Male & Female \\
\hline $3-10$ & $22.706 \mathrm{~kg}+504.3$ & $20.315 \mathrm{~kg}+485.9$ \\
\hline $10-18$ & $17.686 \mathrm{~kg}+652.2$ & $13.384 \mathrm{~kg}+692.6$ \\
\hline$>18^{\star}$ & $15.057 \mathrm{~kg}+692.2$ & $14.818 \mathrm{~kg}+486.6$ \\
\hline
\end{tabular}

Source: FAO. 2001. [21]

Table 3: BMR kcal/day based on body weight $(\mathrm{kg})$

\begin{tabular}{|c|c|c|}
\hline \multirow{2}{*}{ Age years } & \multicolumn{2}{|c|}{ Gender } \\
\cline { 2 - 3 } & Male & Female \\
\hline $2-5$ & $\mathrm{NG}^{*}$ & $\mathrm{NG}$ \\
\hline $5-10$ & 1.35 & 1.35 \\
\hline $10-15$ & 1.52 & 1.48 \\
\hline $15-18$ & 1.56 & 1.46 \\
\hline$>18$ & 1.53 & 1.53 \\
\hline
\end{tabular}

$\mathrm{NG}^{*}=$ Not given; Source: FAO. 2001. [21]

Table 4: Mean physical activity level (PAL) for sedentary or light physical movement

The TEE in excess weight is then the difference between TEE of reference weight and that of overweight or obese weight. The total net energy requirement for excess weight consists then of energy deposited in excess weight and the total energy expenditure for excess weight. As the TEE is commonly given in terms of kcal/day, and the time required for the development of overweight and obesity could vary, the energy deposited in excess weight and TEE are presented separately. The TEE is eventually necessary to find out the extra amount of food required for the maintenance of overweight and obese weight.

The cost of food energy (GE) for overweight and obesity: In the estimation of energy cost for overweight and obesity, allowances for the losses during digestion, absorption and metabolism are considered so that the excess food requirement is not underestimated. An easier and valid means of considering the losses lie on the knowledge of the efficiency of conversion of food energy to body fat. At a community level the average efficiency of conversion of food energy to body energy range from 28\% - 34\% [14]. The median is estimated at $30 \%$. At individual level, the efficiency of conversion could vary based on the composition of food, the genetic makeup of individuals, age, gender and some external factors like health. However, for simple stomached species the average efficiency of the conversion of food energy to fat vary little [22]. Therefore, the inverse of the efficiency of conversion (100/30) multiplied by the energy deposited as excess fat could reliably give the extra cost of food energy for overweight and obesity.

The relationship between the energy expended for excess weight and the energy density of food can give the amount of food used for overweight and obesity. The energy density of food can vary according to food composition. A satisfactory per capita food energy supply with allowances for spoilage and plate wastage is estimated at $2900 \mathrm{kcal}$, which is generated from $1.15 \mathrm{~kg}$ cereal equivalent [23,24]. Conversely $1 \mathrm{~kg}$ cereal equivalent provides $2522 \mathrm{kcal}$, or the average food energy density is $2522 \mathrm{kcal} / \mathrm{kg}$. Cereal equivalent represents the total amount of food energy derived from plant products and that fraction of animal product with its energy generated from cereals, but not from forages nor plant residues and meal byproducts. Accordingly, the cost of food energy for excess weight divided by the mean energy density of common food gives the amount of food expended for excess body weight.

The amount of excess food that leads to overweight and obesity in a community: The information on the number of overweight and obese people, in a locality, country, region or the world could either be directly obtained using body weight and height measurements, or it could be calculated indirectly using the population number of different sex and age classes and the prevalence (\%) of overweight and obesity corresponding to each sex and age classes. The desired information on the prevalence of overweight and obesity for different age classes is scanty. Those that are available are limited to preschool children, adolescents and adults without any further classification and the ones given to children and adolescence are mostly identical $[9,25,26]$. The population number of each sex and age class is multiplied by the prevalence rate given in Table 5 and the estimate number of overweight and obese persons until the age of 18 years. For adults the different prevalence levels indicated in the same Table 5 are applied.

\begin{tabular}{|c|c|c|c|c|}
\hline \multirow{2}{*}{ Age groups } & \multicolumn{2}{|c|}{ Male } & \multicolumn{2}{c|}{ Female } \\
\cline { 2 - 5 } & Overweight & Obese & Overweight & Obese \\
\hline$<5$ years & 13 & 5 & 14 & 7 \\
\hline 5 - $\leq 18$ years & 13 & 5 & 14 & 7 \\
\hline$>18$ years & 27 & 10 & 26 & 13 \\
\hline
\end{tabular}

Source: Marie et al. 2014 [25]

Table 5: Global prevalence (\%) of overweight and obesity 
The sum of the levels of food energy contributing to minimum excess weight in each gender, age and body status classes multiplied by the number of overweight and obese people (Table 6) give the amount of excess food energy consumed to develop the unhealthy body weight in a community (Model 1).

\begin{tabular}{|c|c|c|c|c|c|c|}
\hline \multirow{2}{*}{ Age classes } & \multicolumn{2}{|c|}{ Total population } & \multicolumn{2}{c|}{ Number of overweight } & \multicolumn{2}{c|}{ Number of obese } \\
\cline { 2 - 7 } & Male & Female & Male & Female & Male & Female \\
\hline$<5$ years & 325035171 & 304277421 & 42908000 & 43377000 & 16503100 & 21688400 \\
\hline $5-<10$ years & 251837901 & 234762847 & 41453000 & 41707000 & 15943350 & 20853400 \\
\hline $10-<15$ years & 309124320 & 298922676 & 40382000 & 40526000 & 15531450 & 20263200 \\
\hline $15-\leq 18$ years & 245974350 & 230427349 & 31887000 & 32089000 & 12264250 & 16044300 \\
\hline$>18$ years & 3574670587 & 3524124644 & 660726000 & 643466000 & 244713000 & 321732900 \\
\hline
\end{tabular}

Calculated based on global population census (US census. 2015) [27] and global

Overweight and obesity prevalence (Marie et al. 2014) [25]

Table 6: Global total, overweight and obese population classified according to sex and age

Assuming the global average energy density of cereal equivalent (or food) is $2522 \mathrm{kcal} / \mathrm{kg}$, the grand sum of food energy expended for overweight and obesity divided by this value results in the amount of food (cereal equivalent) expended for the synthesis and maintenance of excess weight.

\section{Results and discussion}

The energy deposited as excess weight can be calculated as long as the desired pieces of information on reference (normal) weight, overweight, obese weight, proportion of body fat in excess weight, the energy value of body fat are available. The energy in excess weight, the efficiency of conversion of food energy to fat, the energy density of common food and the size of the population in each gender and age classes, which are affected by excess weight, can give the energy cost of overweight and obesity. The following model is developed to analyze the food energy cost of excess weight in a defined group of population in a community.

\section{Model 1: Excess food expended for the development of overweight and obesity in a community}

$$
\mathrm{PEF}=\sum_{\mathrm{i}=1}^{\mathrm{n}}[(\mathrm{OWi}-\mathrm{Rwi}) \times 0.72 \times 9 \times 100 / 30 \times \mathrm{Pni}]+\underset{\mathrm{i}=1}{\left.\left.\sum(\underset{\mathrm{OB}}{\mathrm{i}}-\mathrm{Rwi}) \times 0.72 \times 9 \times 100 / 30\right] \times \mathrm{Pni}\right]}
$$

$\mathrm{PEF}=$ the sum of the excess food energy expended for minimum overweight and obese weight in a Population

$\mathrm{n}=$ number of population classes, classified according to gender and age groups

$\mathrm{i}=$ population class $\mathrm{i}$

OWi $=$ overweight of population class $\mathrm{i}$

$\mathrm{OBi}=$ Obese weight of population class $\mathrm{i}$

$\mathrm{RWi}=$ reference weight of population class $\mathrm{i}$

$0.72=$ the proportion of fat in excess weight

$9=$ the energy value of fat in Mcal $/ \mathrm{kg}$ or Mcal $/ 0.001$ ton

$100 / 30=$ the inverse of the efficiency of conversion of food energy to body fat

Pni $=$ Size of the population class $\mathrm{i}$

The two sex and five age classes in addition to three body condition classes are supposed to make the mixed size of the population with excess weight; and the interest is to find out the minimum excess food expended for overweight and obesity. The minimum food cost of overweight and obesity in a community can be calculated using the following equations.

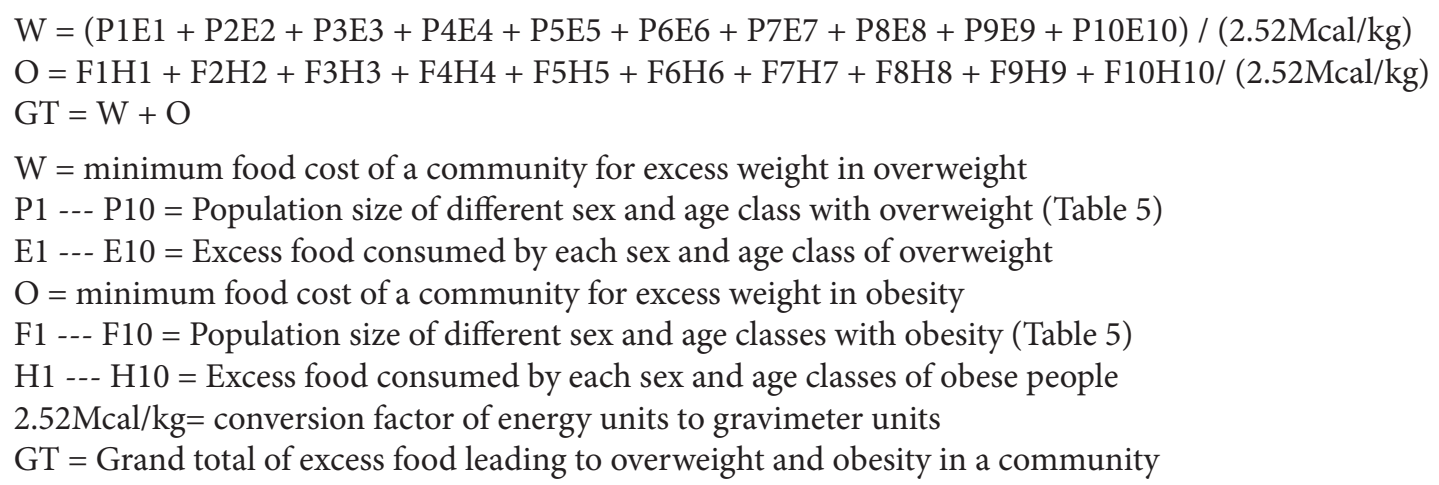


TEE for excess weight in a community: The food expended for excess body weight consists of both food energy deposited as fat and the extra total energy expended for the synthesis and maintenance of the extra weight. The equation in the last page deals only with the energy deposited as fat; the TEE needs to be included because it forms meaningful cost of excess food for the maintenance of excess weight post its formation. Mathematical models are therefore formulated to show the excess food required to maintain overweight and obesity.

\section{Model 2. Extra food energy requirement for the maintenance of excess weight in a community

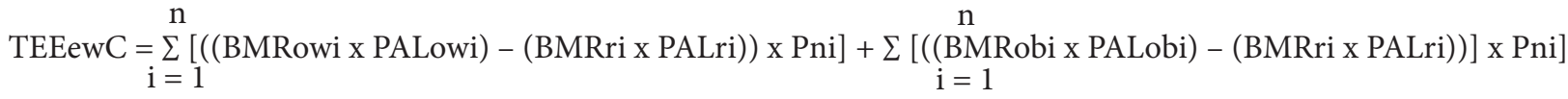

TEEewC $=$ The sum of excess total energy expenditure due to overweight and obesity in a community

$\mathrm{n}=$ number of population classes classified according to gender and age groups

$\mathrm{i}=$ population class $\mathrm{i}$

owi = overweight of population class $i$

obi $=$ obese weight of population class $i$

$\mathrm{BMR}=$ basal metabolic rate of population class $\mathrm{i}$

TEE = total energy expenditure of population class $\mathrm{i}$

$\mathrm{PAL}=$ physical activity level of population class $\mathrm{i}$

$\mathrm{ri}=$ reference population class $\mathrm{i}$

Pni $=$ Size of population class $\mathrm{i}$

Two sex and five age classes, together with three body status classes, are considered to make the mixed size of the population; and the objective is to find out the minimum excess food expended for the maintenance of overweight and obesity in a community. The following equations are employed to find out the food cost of a community for the total energy expenditure on the maintenance of excess weight.

$\mathrm{T}=(\mathrm{P} 1 \mathrm{~L} 1+\mathrm{P} 2 \mathrm{~L} 2+\mathrm{P} 3 \mathrm{~L} 3+\mathrm{P} 4 \mathrm{~L} 4+\mathrm{P} 5 \mathrm{~L} 5+\mathrm{P} 6 \mathrm{~L} 6+\mathrm{P} 7 \mathrm{~L} 7+\mathrm{P} 8 \mathrm{~L} 8+\mathrm{P} 9 \mathrm{~L} 9+\mathrm{P} 10 \mathrm{~L} 10) / 2.52 \mathrm{Mcal} / \mathrm{kg}$

$\mathrm{S}=(\mathrm{F} 1 \mathrm{R} 1+\mathrm{F} 2 \mathrm{R} 2+\mathrm{F} 3 \mathrm{R} 3+\mathrm{F} 4 \mathrm{R} 4+\mathrm{F} 5 \mathrm{R} 5+\mathrm{F} 6 \mathrm{R} 6+\mathrm{F} 7 \mathrm{R} 7+\mathrm{F} 8 \mathrm{R} 8+\mathrm{F} 9 \mathrm{R} 9+\mathrm{F} 10 \mathrm{R} 10) / 2.52 \mathrm{Mcal} / \mathrm{kg}$

$\mathrm{GT}=\mathrm{T}+\mathrm{S}$

$\mathrm{T}=$ The sum of a community food cost for excess TEE in case of overweight

P1 --- P10 = Population size of different sex and age class with overweight (Table 5)

L1 --- L10 = The amount of food energy required by each class to maintain excess weight in overweight

$\mathrm{S}=$ The sum of a community food cost for excess TEE in case of obesity

F1 --- F10 = Population size of different sex and age classes with obesity (Table 5)

R1 --- R10 = The amount of food energy required by each class to maintain excess weight in obese population

$2.52 \mathrm{Mcal} / \mathrm{kg}=$ Conversion factor of food energy unit to gravimeter unit

$\mathrm{GT}=$ Grand total of excess food required by a community to maintain excess weight in overweight and obesity

The Models are designed to:

1. Determine the excess weight in conditions of overweight and obesity and the extra amount food energy or food expended to produce them

2. Estimate the total energy expenditure for excess weight in conditions of overweight and obesity and

3. Calculate the daily cost of the extra food for the maintenance of excess weight.

The major variables, excess body weight and extra food required to produce it are considered. Sex and age classes with the corresponding population size are contained to make the approach a realistic one. In reference to the mathematical equations, the biological and nutritional aspects are adequately translated. The symbols are defined and their dimensions whenever necessary are determined. Adequate number of equations is formulated to define the problem. Subject to freedom from numerical and computational errors, the models can be used to serve the purpose for which they are designed.

\section{The application of the models with an example of the global prevalence of overweight and obesity}

Using Model 1 and the pieces of information given in Tables 1, 2 and 6, the global energy cost for excess weight in overweight and obesity is calculated and the results are presented in Table 7. The total overweight and obese population for the given year (2015) is estimated at 2.324 billion consisting of 1618.52 Million overweight and 705.54 Million obese people with the prevalence rate of $22.31 \%$ and $9.73 \%$ of the total population respectively.

According to the information given in Table 7, the energy cost of excess weight in global overweight and obese population is found to be 659.445 million Gcal (Giga calorie = 1 million Mcal). The female population is more affected (55.7\%) than the male population, because of the higher proportion (52\%) of female population with excess weight, higher number (322 million) of adult obese woman than adult obese men ( 245 million), and the steady increase of excess weight with age and higher tendency in favor of the female population. 


\begin{tabular}{|c|c|c|c|c|c|c|}
\hline Gender & Body status & Age & $\begin{array}{c}\text { Excess wt. } \\
\text { [EW] }\end{array}$ & $\begin{array}{c}\text { Food energy } \\
\text { [E] cost/given EW }\end{array}$ & $\begin{array}{l}\text { Population } \\
\text { in millions }\end{array}$ & $\begin{array}{l}\text { Total E cost in } \\
\text { million Mcal }\end{array}$ \\
\hline \multirow{10}{*}{ Male } & \multirow{5}{*}{ Overweight } & $<5$ years & 2.84 & 61.28 & 42.91 & 2629.47 \\
\hline & & $5-<10$ years & 3.88 & 83.72 & 41.45 & 3470.55 \\
\hline & & $10-<15$ years & 7.99 & 172.41 & 40.38 & 6962.19 \\
\hline & & $15-\leq 18$ years & 9.95 & 214.70 & 31.89 & 6846.17 \\
\hline & & $>18$ years & 8.8 & 189.89 & 660.73 & 125462.88 \\
\hline & \multirow{5}{*}{ Obese } & $<5$ years & 4.2 & 90.63 & 16.50 & 1495.64 \\
\hline & & $5-<10$ years & 8.71 & 187.94 & 15.94 & 2996.46 \\
\hline & & $10-<15$ years & 19.82 & 427.68 & 15.53 & 6642.43 \\
\hline & & $15-\leq 18$ years & 24.87 & 536.64 & 12.26 & 6581.55 \\
\hline & & $>18$ years & 24.47 & 528.01 & 244.71 & 129211.81 \\
\hline \multirow{10}{*}{ Female } & \multirow{5}{*}{ Overweight } & $<5$ years & 2.87 & 61.93 & 43.38 & 2686.29 \\
\hline & & $5-<10$ years & 3.77 & 81.35 & 41.71 & 3392.83 \\
\hline & & $10-<15$ years & 8.13 & 175.43 & 40.53 & 7109.44 \\
\hline & & $15-\leq 18$ years & 10.28 & 221.82 & 32.09 & 7118.04 \\
\hline & & $>18$ years & 13.2 & 284.83 & 643.47 & 183278.16 \\
\hline & \multirow{5}{*}{ Obese } & $<5$ years & 4.64 & 100.12 & 21.69 & 2171.48 \\
\hline & & $5-<10$ years & 12.86 & 277.49 & 20.85 & 5786.67 \\
\hline & & $10-<15$ years & 24.71 & 533.19 & 20.26 & 10804.18 \\
\hline & & $15-\leq 18$ years & 15.79 & 340.72 & 16.04 & 5466.56 \\
\hline & & $>18$ years & 20.07 & 433.07 & 321.73 & 139333.02 \\
\hline Grand total & & & & & 2324.06 & 659445.82 \\
\hline
\end{tabular}

Table 7: The food energy [E] cost for overweight and obesity

Using the conversion factor of food energy unit to gravimeter unit, as given in Model 1, the total amount of food expended for the development of global overweight and obese weight is 261.684 million tons.

Model 2 and the information on basal metabolic rate, physical activity level and the number of overweight and obese people (Tables 3, 4 and 6) are used to calculate the community extra food energy expended for the maintenance of excess weight in conditions of overweight and obesity. Accordingly, the global food energy cost for the maintenance of excess bodyweight is 656.9 million Mcal/ day or $239.8 \mathrm{Million} \mathrm{Gcal} / \mathrm{year}$. This can be interpreted in gravimetric value as 260.5 thousand ton/day or 95.07 million tons/year.

Assuming that the average annual food production per hectare is 2.64 tons [28] and this sustains, land area equivalent to 100.26 million hectare is used to produce enough food to meet the cost for global excess body weight and 36.43 million hectare is used every year for the maintenance of the excess body weight. These values form the bases for the estimation the direct extra load on the environment (soil-, water- and atmosphere degradation plus loss of biodiversity) and indirect impact on human health. The impacts of intensive food production system in order to feed the growing world population on human nutrition and health are well-documented [29]. The current level of overweight and obesity at national, regional or global context, and the anticipated trend of growth, predispose the furtherance of the negative impacts on the environment and human health.

\section{Conclusion}

The challenges of overweight and obesity are manifold. Most often, those that have direct effect on health are duly considered for improvement. Indirect impacts that primarily concern the degradation of the environment followed by its consequences on community health are hardly discussed. Worldwide huge amount of food is misused for the development of excess weight and its maintenance. This implies additional load on the supply side of food management, which fundamentally over-demands production resources and technological inputs. Expanded and intensified agricultural practices degrade the environment at first and then invoke indirect human health problems.

\section{References}

1. Asfaw A (2006) The effects of obesity on doctor diagnosed chronic diseases in Africa: empirical results from Senegal and South Africa. J Public Health Policy 27: 250-64.

2. Cappuccio FP, Kerry SM, Adeyemo A, Luke A, Amoah AG, et al. (2008) Body size and blood pressure: an analysis of Africans and the African diaspora. Epidemiology 19: 38-46.

3. WHO (2004) Global Strategy on Diet, Physical Activity and Health, Geneva, Switzerland. 
4. WHO (2015) Obesity and overweight.

5. WHO (2005) Preventing chronic diseases: a vital investment, Geneva, Switzerland.

6. Kelly T, Yang W, Chen CS, Reynolds K, He J (2008) Global burden of obesity in 2005 and projections to 2030. Int J Obes 32: $1431-7$.

7. Siervo M, Grey P, Nyan OA, Prentice AM (2006) Urbanization and obesity in the Gambia: a country in the early stages of demographic transition. Eur J Clin Nutr 60: 455-63.

8. Ziraba AK, Fotso JC, Ochako R (2009) Overweight and obesity in urban Africa: A problem of the rich or poor? BMC Public Health 9: 465-74.

9. de Onis M, Blössner M, Borghi E (2010) Global prevalence and trends of overweight and obesity among preschool children. Am J Clin Nutr 92: 1257-64.

10. Ello-Martin JA, Ledikwe JH, Rolls BJ (2005) The influence of portion size and energy density on energy intake: implications for weight management. Am J Clin Nutr 82: 236S-241S

11. Reilly JJ, Kelly J (2011) Long-term impact of overweight and obesity in childhood and adolescence on morbidity and premature mortality in adulthood: Systemic review. Int J Obes 35: 891-8.

12. Cole JT, Flegal MK, Nicholls D, Jackson AA (2007) Body mass index cutoffs to define thinness in children and adolescents: international survey. BMJ 335: 194-7.

13. Foster GD, Wadden TA, Mullen JL, Stunkard AJ, Wang J, et al. (1988) Resting energy expenditure, body composition and excess weight in the obese. Metabolism 37: 467-72.

14. Donato K, Hegsted DM (1985) Efficiency of utilization of various sources of food energy for growth. Proc Natl Acad Sci USA 82: 4866-70.

15. WHO (2006) WHO Child Growth Standards: Methods and development Length/height for age, weight-for-age, weight-for-length, weight-for-height and body mass index-for-age, Department of Nutrition for Health and Development, Geneva, Switzerland.

16. WHO (2007) Growth References (Height-for-age 5-19 years).

17. Marshal WA (1981) Body Weight and Height by Countries, Joint FAO/ WHO/ UNU Expert Consultation on Energy and Protein Requirement, Rome 5 to 17 October 1981, Leicestershire, England.

18. Melanson KJ, Summers A, Nguyen V, Brosnahan J, Lowndes J, et al. (2012) Body composition, dietary composition, and components of metabolic syndrome in overweight and obese adults after 12-week trial on dietary treatments focused on portion control, energy density, or glycemic index. Nutr J 11: 57-66.

19. Webester JD, Hesp R, Garrow JS (1984) The composition of excess weight in obese women estimated by density, total body water, and total body potassium. Hum Nutr Clin Nutr 38: 299-306.

20. Elert G (2004) Energy density of fats In The physics fact book.

21. FAO (2001) Human energy requirement, Report of a joint FAO/WHO/UNU Expert Consultation. Rome 17 - 24 October 2001.

22. Blaxter KL (1989) Energy metabolism in animals and man, Cambridge University Press, Cambridge, UK.

23. WHO (2015) Global and regional food consumption patterns and trends.

24. USDA (2002) Profiling food consumption in America In United States Department of Agriculture. Agricultural Fact Book 2001-2002.

25. Ng M, Fleming T, Robinson M, Thomson B, Graetz N, et al. (2014) Global, regional and national prevalence of overweight and obesity in children and adults during 1980-2013: a systematic analysis for the Global Burden of Disease Study 2013. Lancet 384: 766-81.

26. WHO (2015) Obesity and overweight, Factsheet No 311.

27. US Census (2013) World midyear population by age and Sex. International Data Base (IDB).

28. Cassidy ES, West PC, Gerber JS, Foley JA (2013) Redefining agricultural yields: from tonnes to people nourished per hectare. Environ Res Lett 8: doi:10.1088/17489326/8/3/034015.

29. Habte TY, Krawinkel M (2015) Nutritional and Health Implications of Conventional Agriculture - A Review. J Nutr Health Sci 2: 102. 